\title{
Meet DAD, the dynamic assessment dashboard
}

\author{
Raphaël Grolimund
}

\begin{abstract}
This paper doesn't present the findings of an experiment. It presents a tool created (and still under active development) to put an specific teaching method, dynamic assessment, into practice through an online dashboard.

This paper explores if students felt comfortable with this teahing method, if it helped them take control of their learning and how they felt with this dashboard.

Even if the tasks to do where both individual and group tasks, only the individual activities are analyzed. This tool is used for two years, but data presented in this paper are only those collected last year (Fall 2016). Data were anonymised, cleaned and published on Zenodo (10.5281/zenodo.290129).
\end{abstract}

\section{Introduction}

In higher education, most of the time students are evaluated by mid-term and/or final exams. This means that the student's understanding and learning is evaluated on predefined day and that (s)he has to succeed that day. Failing is not allowed, however it could be good to help students learn. The idea was to allow students to fail thanks to a dynamic assessment (Sharples et al., 2014). Instead of giving student only one bullet, it allows them to fail and learn to improve until they succeed.

The Dynamic assessement dashboard (DAD) has been created to assess students dynamically throughout the semester. Giving them the control on their learning (pace, tasks) leads to self-regulation (Hattie, 2012) and was expected to increase students' motivation. Getting a bonus for completing a set of tasks includes gamification features that supports students' engagement (Hamari et al., 2016).

DAD also includes some gamification mechanics like bonuses (Deterding, Dixon, Khaled, \& Nacke, 2011; Muletier, Bertholet, \& Lang, 2014). DAD has been created as a personal dashboard. A student can't access another student's dashboard and achievements.

DAD is intended to increase students' self-efficacy (Zimmerman, 2000) whatever their learning style is. The mix of individual and group activities should help students reach the zone of proximal development as defined by Vygotsky (Vygotsky, 1978).

\section{DAD}

The idea of DAD is born from the combination of the reading of the Open University's Innovating pedagogy 2014 report (Sharples et al., 2014) and the observation of how young children's learning is assessed. The former presents the concept of dynamic assessment to give the learner personalized assessement and the latter is based on simple stamps indicating when a task has been successfully achieved. DAD is an attempt to put that in an online dashboard that displays activities defined by the teacher. All tasks are meant to 
help students reach the course's objectives. Students choose what to do and when to do it. If the teacher allows it, they can even choose if they want to do it or not.

Activities can have a deadline (at the end of the semester) or a precise date (for activities made once in class). There can be individual and/or group activties.

A task can be in a limited number (e.g. there are a linited number of slots for presenting in front of the class) or not (all the students can do them). It's possible to add bonuses.

The idea of dynamic assessment lying behind DAD also means that a student can submit a proposal several times to improve it until it's validated.

The process looks like this:

1. the student sumbits a proposal

2. the teacher reviews it and

3. (s)he validates or rejects it

If the proposal is validated, it's displayed in DAD (including a short feedback).

If the proposal is rejected, the teacher gives a feedback (currently by email) to help the student improve and submit again. This is how DAD allows students to fail.

\section{Implementation of DAD in the course}

DAD is used for 2 years (Fall 2015 and Fall 2016) in a Bachelor course given at the University of applied sciences in Geneva.

This 60 hours course is entitled "Formation des usagers en bibliothèques" (course in French) and lasts 10 weeks (6 hours per week). The course is optional. Students learn to give a lecture by doing it (at the end of the semester).

During the first year of teaching this course (Fall 2014), the assessment was classisc Two graded homeworks (checklist and lesson plan - see table 1) during the semester and one final exam (giving a 45 lecture including interaction). But in order to let students learn at their own pace, it seemed not appropriate to define when they had to achieve the mid-term tasks. DAD was designed to let each student work at his own pace.

The rule of the Fall 2016 course was to reach 40 points to get the ECTS credits. The "final exam" remained the same and provided a maximum of 24 points. Students had to complete with additional points collected through activities available and explained in DAD. All activities were optional, but students had to do something to reach 40 points. The upper limit of points reachable with DAD was put to 40 points (even if the total of points in the dashboard was 44). Tasks were divided in groups (see table 1).

Table 1: Group of activities and related activities number

\begin{tabular}{llll}
\hline \hline Group name & Group description & Activties type & Activities number \\
Sharing & students share interesting findings & individual & $\# 1 \# 2 \# 3 \# 4(+\# 5)$ \\
Presenting & students practice before the final exam & individual & $\# 10 \# 14$ \\
Explaining & students who dig deeper in the topic & individual & $\# 16 \# 41$ \\
Visual Literacy & students use icons not text in slides & individual & $\# 21 \# 22 \# 23(+\# 24)$ \\
Video making & students produce a video tutorial & group & $\# 7 \# 8$ \\
Checklist & students prepare a lecture & group & $\# 25 \# 26 \# 27 \# 28$ \\
Lesson plan & students make their lesson & group & $\# 29 \# 30 \# 31 \# 32$ \\
Peer-grading & students assess someone else's work & group & $\# 33$ \\
\hline
\end{tabular}


There were 13 individual activities distributed in 4 first groups listed above: five 1-pt activities ( + two 1-pt bonus), five 2-pt activities and one 3-pt activitiy. The list of Fall 2016 activities are in the appendix. Completed activities are in color in DAD's student interface and the other ones remains in black and white. Figure 1 shows DAD's student interface.
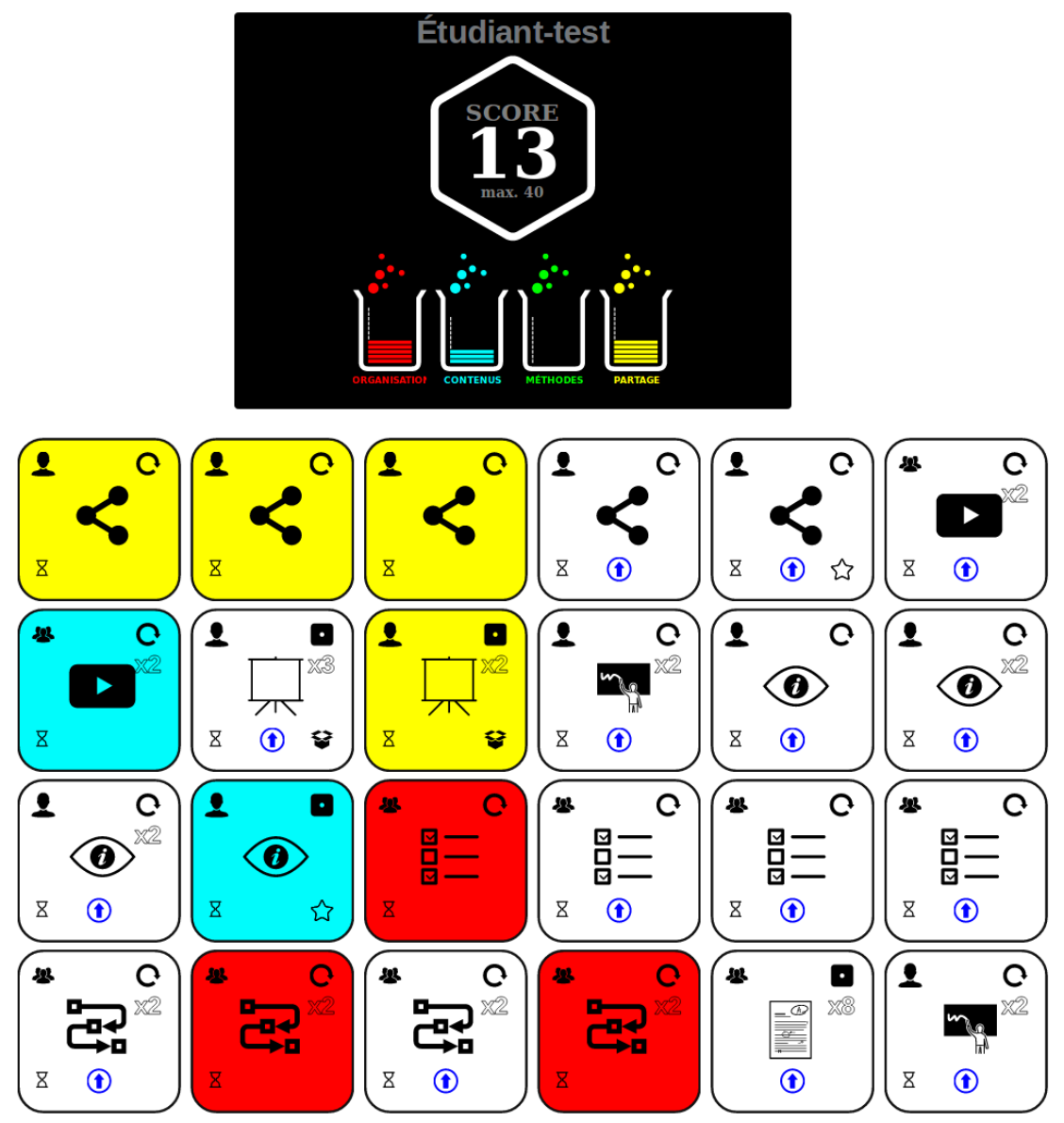

Figure 1: DAD's student interface

\section{Students usage}

195 individual tasks were submitted by 21 of the 23 students (a little bit more than 9 tasks per student out of a maximum of 11 - bonus included). Students validated 146 submissions (about 7 tasks per student) making 29 additional bonus.

Table 2: Ranking of individual activities by number of submissions

\begin{tabular}{lllll}
\hline \hline actID & nb of submissions & nb of rejections & activity weight & comment \\
$\# 21$ & 36 & 18 & 1 & Visual Literacy \\
$\# 23$ & 30 & 13 & 2 & Visual Literacy \\
$\# 22$ & 23 & 8 & 2 & Visual Literacy \\
$\# 1$ & 22 & 4 & 1 & Sharing
\end{tabular}




\begin{tabular}{lllll}
$\# 3$ & 21 & 4 & 1 & Sharing \\
$\# 4$ & 19 & 1 & 1 & Sharing \\
$\# 2$ & 18 & 0 & 1 & Sharing \\
$\# 24$ & 15 & N/A & 1 & Bonus \\
$\# 5$ & 14 & N/A & 1 & Bonus \\
$\# 41$ & 13 & 1 & 2 & Explaining \\
$\# 16$ & 11 & 0 & 2 & Explaining \\
$\# 10$ & 3 & 0 & 3 & Presenting \\
$\# 14$ & 1 & 0 & 2 & Presenting \\
\hline
\end{tabular}

Even though, nothing was submitted in the 2 first weeks, 3 students (early birds in table 3) sent all their individual submissions within the 5 first weeks of the course. On the other hand, 4 students (latecomers in table 3) submitted almost or absolutely nothing before week 8 (the week before Christmas). $15 \%$ of the individual submissions were sent during the 2-week Christmas break.

Table 3: When do students submit individual tasks: comparison of early birds, latecomers and the overall class mean

\begin{tabular}{|c|c|c|c|c|c|c|c|}
\hline week & $\begin{array}{l}\text { early bird } \\
\# 1 \\
(\mathrm{n}=10)\end{array}$ & $\begin{array}{l}\text { early bird } \\
\# 2 \\
(\mathrm{n}=13)\end{array}$ & $\begin{array}{l}\text { early bird } \\
\# 3 \\
(\mathrm{n}=10)\end{array}$ & $\begin{array}{l}\text { overall } \\
\text { mean } \\
(\mathrm{n}=195)\end{array}$ & $\begin{array}{l}\text { latecomer } \\
\# 1 \\
(\mathrm{n}=7)\end{array}$ & $\begin{array}{l}\text { latecomer } \\
\# 2 \\
(\mathrm{n}=8)\end{array}$ & $\begin{array}{l}\text { latecomer } \\
\# 3 \\
(\mathrm{n}=8)\end{array}$ \\
\hline \multicolumn{8}{|l|}{$\# 1$} \\
\hline \multicolumn{8}{|l|}{$\# 2$} \\
\hline$\# 3$ & $90 \%$ & $46 \%$ & $50 \%$ & $27 \%$ & & & \\
\hline$\# 4$ & $10 \%$ & $54 \%$ & $40 \%$ & $26 \%$ & & & \\
\hline$\# 5$ & & & $10 \%$ & $9 \%$ & & & \\
\hline$\# 6$ & & & & $4 \%$ & $14 \%$ & & \\
\hline$\# 7$ & & & & $10 \%$ & & $25 \%$ & \\
\hline$\# 8$ & & & & $6 \%$ & $41 \%$ & $50 \%$ & $25 \%$ \\
\hline holidays & & & & $4 \%$ & & & \\
\hline holidays & & & & $11 \%$ & & $25 \%$ & $75 \%$ \\
\hline$\# 9$ & & & & $2 \%$ & $41 \%$ & & \\
\hline$\# 10$ & & & & & & & \\
\hline
\end{tabular}

It's no surprise that students didn't work at the same time, but it's interesting to discover that some students seemed to have scheduled their individual work (early riser and night owl in table 4). Most individual submissions were concentrated in the afternoon.

Table 4: Students individual submissions time

\begin{tabular}{llll}
\hline \hline Time & early riser $(\mathrm{n}=11)$ & night owl $(\mathrm{n}=10)$ & overall class mean $(\mathrm{n}=195)$ \\
morning $(06: 00-12: 00)$ & 10 & - & 28 \\
afternoon $(12: 00-18: 00)$ & $1(12: 57)$ & $2(17: 57-17: 59)$ & 104 \\
evening $(18: 00-24: 00)$ & - & 5 & 55 \\
night (00:00-6:00) & - & 3 & 8 \\
\hline
\end{tabular}

As shown in table 5, a lot of submissions were sent on Thursday, the day the course took place. Surprisingly, no submission was sent on Wednesday. This table also shows that individual submissions were more likely 
to be rejected on Thursday (33\%), Monday (30\%) and Tuesday (29\%).

Table 5: Individual activities rejection rate by weekday

\begin{tabular}{llll}
\hline \hline Weekday & $\#$ of rejections & \# of submissions & rejection rate \\
Monday & 9 & 30 & $30 \%$ \\
Tuesday & 10 & 35 & $29 \%$ \\
Wednesday & 0 & 0 & N/A \\
Thursday & 24 & 72 & $33 \%$ \\
Friday & 1 & 18 & $6 \%$ \\
Saturday & 1 & 16 & $6 \%$ \\
Sunday & 4 & 24 & $17 \%$ \\
\hline
\end{tabular}

$79 \%$ of the students whose first submissions were rejected (sometimes several times) finally successfully validated the task (table 6 ).

Table 6: Students' behaviour after an initial rejection

\begin{tabular}{lll}
\hline \hline Times submitted and rejected & Validated & Not validated \\
1 time & 12 & 3 \\
several times & 7 & 2 \\
\hline
\end{tabular}

Two students validated all the individual tasks and two students didn't submit a single one, relying on group tasks only (table 7).

Table 7: Comparison of students individual completed tasks and course attendance

\begin{tabular}{lll}
\hline \hline tasks completed & \# of students & course attendance average \\
13 & 2 & $100 \%$ \\
12 & 1 & $100 \%$ \\
11 & 7 & $93 \%$ \\
10 & 0 & - \\
9 & 3 & $78 \%$ \\
8 & 1 & $44 \%$ \\
7 & 3 & $93 \%$ \\
6 & 0 & - \\
5 & 1 & $100 \%$ \\
4 & 1 & $100 \%$ \\
3 & 1 & $6 \%$ \\
2 & 0 & - \\
1 & 1 & $11 \%$ \\
0 & 2 & $89 \%$ \\
\hline
\end{tabular}




\section{Analysis}

Students gave priority to those who lead to a bonus. Table 2 shows that they didn't seem to choose the tasks based on their weight: 5 out of the 7 most submitted tasks were only worth 1 point. Likewise, the difficulty of the task didn't seem to be the students' main criteria: the top 3 rejected activities are the same as the top 3 submitted activities. It looks like gamification worked.

Students had various behaviours regarding when to submit a task (tables $3 \& 4$ ). It seems that many of them took advantage of DAD and did their "homework" when it was convenient to them. DAD's goal seems to be reached. It is worth mentioning that after the presentation of the tool during the first lesson (week 1), students asked for a second explanation on week 2. This is probably the reason why no task was submitted during the 2 first weeks. Additionally, we can imagine that students didn't feel the urge of completing the tasks at the very beginning of the semester...

It's interesting to mention that few submissions came at the end of the semester (only $2 \%$ during week 9). As the end of the semester is usually full of assessments in all the courses students attend, it could mean that students planned to make the activities earlier in the semester in order to lighten the burden of the end of the semester. But we can't test that yet.

This year's formula enabled students to pass the course by completing tasks in DAD, possibly without attending the course. But the opposite happened: students who didn't attend the course regularly finished with a lower score in DAD than students who didn't miss any lecture. It's interesting to notice that the 2 students who didn't submit any individual activity attended the course regularly. These students wre probablyb not comfortable with the dashboard and/or dynamic assessment. Even if there is no correlation between the use of DAD and the course attendance, table 7 shows that students who completed almost all individual tasks have an high course attendance rate. It shows at least that giving students the control doesn't have a bad influence on the course attendance.

Giving students the right to fail and submit again seems to work as 4 out of 5 students who initially failed finally succeeded (table 6). It's also nice to see that most students were not discouraged by their inital failure: only 3 of them (12.5\%) gave up at that point.

\section{Students feedback}

Students were asked to give a feedback to the teacher, in class, during the last lesson of the semester. After they listed the things they would like to keep, to change and to add to the course, they had to give their priority based on each of the 3 lists.

DAD appeared in the "to keep" list. When this list was refined by priority, DAD was second in the list. DAD also appeared in the "to change" list. In that list, students ranked "being able to answer to the feedback of the teacher" third and a few improvement expressed in class forth. The will of students to answer to the teacher's feedback was a surprise, because DAD has been designed to support their learning and not as a channel to communicate. But this idea and the other ones expressed in class will be implemented in future releases of DAD.

Students also mentionned that they would like to be able to access to what they submitted. This was not possible in DAD and it's a technical problem that has to be fixed quickly.

\section{Conclusion}

Even if there a lot of space for improvement in DAD, it appears to please most of the students. Students completed most of the tasks even if they were all optional. 
It also seem to fit their needs, at least for most of the students. They took advantage of being assessed whenever and if they want, and to submit a task several times if needed.

If the students' motivation couldn't evaluated, their feedback was largely positive.

A few privacy concerns need to be fix before releasing the software. The code will be released on Github (https://github.com/grolimur/DAD) later this year and a demo version will be set up in order to let interested people test it.

As the software interface is developped in French, the translation (in English first) is planned.

Some competition features could also be implemented in future versions like the current higher score, "your rank is x" or "this week x students achieved y tasks, and you?". However, these future features will come with the possibility to opt-out because competition os not always good for learning.

\section{Appendix: List of activities}

This is the list of tasks available during the 2016-2017 course (translated from French).

1. Share a reading relevant for the course (1 point)

2. Share a tool useful in a teaching/learning context (1 point)

3. Share an online course related with the course topic (1 point)

4. Share a mobile app useful in a teaching/learning context (1 point)

5. Bonus for achieving 1, 2, 3, and 4 (1 point)

6. Write the script of a video tutorial (2 points)

7. Produce a short video tutorial (2 points)

8. Make a 5 minutes presentation of a reading or a tool in front of the class (3 points)

9. Make a 5 minutes presentation of a reading or a tool to the teacher (2 points)

10. Define a concept related to teaching/learning not seen in class yet (2 points)

11. Understand an explaination only made with icons, no text (1 point)

12. Give an explanation only with icons, no text (2 points)

13. Explain the structure of a permanent identifier only with icons, no text (2 points)

14. Bonus for achieving 11,12 and 13 (1 point)

15. Create a checklist with all the elements needed (1 point)

16. Create a checklist easy to use (1 point)

17. Create a checklist with relevant elements (1 point)

18. Create a checklistwith a neat layout (1 point)

19. Create a lesson plan understandable (2 points)

20. Create a lesson plan with all the elements needed ( 2 points)

21. Create a lesson plan with a realistic timing (2 points)

22. Create a lesson plan with a neat layout (2 points)

23. Doing the peer-grading exercise with care ( 8 points) 
24. Define a teaching method not seen in class yet (2 points)

\section{References}

Deterding, S., Dixon, D., Khaled, R., \& Nacke, L. (2011). From game design elements to gamefulness. In Proceedings of the 15th international academic MindTrek conference on envisioning future media environments - MindTrek '11. Association for Computing Machinery (ACM).

Hamari, J., Shernoff, D. J., Rowe, E., Coller, B., Asbell-Clarke, J., \& Edwards, T. (2016, jan). Challenging games help students learn: An empirical study on engagement flow and immersion in game-based learning. Computers in Human Behavior, 54, 170-179.

Hattie, J.(2012). Visible learning for teachers: maximizing impact on learning. Routledge.

Muletier, C., Bertholet, G., \& Lang, T. (2014). La gamification: ou l'art d'utiliser les mécaniques du jeu dans votre business. Eyrolles. (bibtex: muletier2014)

Sharples, M., Adams, A., Ferguson, R., Gaved, M., McAndrew, P., Rienties, B., et al. (2014). Innovating Pedagogy 2014 (No. Innovation Report 3). (bibtex: sharples2014)

Vygotsky, L. S.(1978). Interaction between learning and development. In Mind in society: the development of higher psychological processes (pp. 79-91). Harvard University Press.

Zimmerman, B. J. (2000, jan). Self-Efficacy: An Essential Motive to Learn. Contemporary Educational Psychology, 25(1), 82-91. 